\title{
Decreased Portal Circulation Augments Fibrosis and Ductular Reaction in Nonalcoholic Fatty Liver Disease in Mice
}

Lingtong Meng, ${ }^{* \dagger}$ Masanori Goto, ${ }^{*}$ Hiroki Tanaka, ${ }^{*}$ Yuki Kamikokura, ${ }^{*}$ Yumiko Fujii, ${ }^{*}$ Yoko Okada, ${ }^{*}$ Hiroyuki Furukawa, ${ }^{\dagger}$ and Yuji Nishikawa*

From the Division of Tumor Pathology, ${ }^{*}$ Department of Pathology, and the Division of Gastroenterological and General Surgery, ${ }^{\dagger}$ Department of Surgery, Asahikawa Medical University, Asahikawa, Japan

Accepted for publication

June 3, 2021.

Address correspondence to Yuji Nishikawa, M.D., Ph.D., Division of Tumor Pathology, Department of Pathology, Asahikawa Medical University, Higashi 2-1-1-1, Midorigaoka, Asahikawa, Hokkaido 0788510, Japan. E-mail: nishikwa@asahikawa-med.ac.jp.

\begin{abstract}
Nonalcoholic fatty liver disease often progresses to cirrhosis and causes liver cancer, but mechanisms of its progression are yet to be elucidated. Although nonalcoholic fatty liver disease is often associated with abnormal portal circulation, there have not been any experimental studies to test its pathogenic role. Here, whether decreased portal circulation affected the pathology of nonalcoholic steatohepatitis (NASH) was examined using congenital portosystemic shunt (PSS) in C57BL/6J mice. Whereas PSS significantly attenuated free radical-mediated carbon tetrachloride injury, it augmented pericellular fibrosis in the centrilobular area induced by a $0.1 \%$ methionine choline-deficient L-amino acid-defined high-fat diet (CDAHFD). PSS aggravated ductular reaction and increased the expression of connective tissue growth factor. Pimonidazole immunohistochemistry of the liver revealed that the centrilobular area of PSS-harboring mice was more hypoxic than that of control mice. Although tissue hypoxia was observed in the fibrotic area in CDAHFD-induced NASH in both control and PSS-harboring mice, it was more profound in the latter, which was associated with higher carbonic anhydrase 9 and vascular endothelial growth factor expression and neovascularization in the fibrotic area. Furthermore, partial ligation of the portal vein also augmented pericellular fibrosis and ductular reaction induced by a CDAHFD. These results demonstrate that decreased portal circulation, which induces hypoxia due to disrupted intralobular perfusion, is an important aggravating factor of liver fibrosis in NASH. (Am J Pathol 2021, 191: 1580-1591; https://doi.org/10.1016/j.ajpath.2021.06.001)
\end{abstract}

Nonalcoholic fatty liver disease (NAFLD), the most common chronic liver disease, includes simple fatty liver and nonalcoholic steatohepatitis (NASH). Although most NAFLD cases appear to be nonprogressive, a recent analysis revealed that the cumulative risk of progression of NAFLD to cirrhosis was $39 \%$ over 8 years of follow-up. ${ }^{1}$ With the progression of NASH-associated cirrhosis, fatty changes in the liver parenchyma could be lost, leading to the notion that a substantial portion of cases of cryptogenic liver cirrhosis might actually be burnt-out NASH. ${ }^{2}$ Furthermore, hepatocellular carcinoma often develops during NAFLD progression, ${ }^{3}$ significantly worsening patient prognosis.

The independent clinical predictors of NAFLD progression include cardiovascular disease, renal impairment, dyslipidemia, and diabetes. ${ }^{1}$ However, mechanisms involved in the progressive fibrosis of NAFLD remain unclear. Xenon computed tomography studies show a more profound decrease in portal blood flow in patients with NASHassociated cirrhosis than in those with hepatitis virus C-associated cirrhosis. ${ }^{4}$ In NAFLD, portal blood flow can be hampered even before the development of fibrosis through hepatocyte swelling due to lipid accumulation and endothelial dysfunction. ${ }^{5,6}$ Although portal circulatory disturbances may contribute to the progression of NASH, this is not yet confirmed experimentally.

Supported by Japan Society for the Promotion of Science grants 15K15107 and 19H03448 (Y.N.), and Japan Agency for Medical Research and Development Research Program on Hepatitis grant 17824875 (Y.N.).

Disclosures: None declared. 
Congenital portosystemic shunts (PSS) develop in a small percentage of C57BL/6J mice. ${ }^{7}$ Whether the disturbance of portal blood flow affected liver pathology in NASH was investigated in the current study. A $0.1 \%$ methionine choline-deficient L-amino acid-defined high-fat diet (CDAHFD) was used to induce NASH-like liver injury with marked steatosis and fibrosis. The effect of PSS was also examined in acute and chronic carbon tetrachloride injury models. Whereas PSS significantly reduced the extent of parenchymal necrosis following a single administration of carbon tetrachloride and decreased liver fibrosis following repeated carbon tetrachloride administrations, it markedly promoted liver fibrosis and ductular reaction in mice fed a CDAHFD. There was enhanced liver parenchymal hypoxia, especially in the centrilobular zone, in mice with PSS, which might explain the differing effects of PSS on these liver injury models. Furthermore, partial ligation of the portal vein in normal, shunt-free mice enhanced liver fibrosis and ductular reactions induced by a CDAHFD. The present study provides evidence suggesting that decreased portal circulation, which is associated with tissue hypoxia, is an important aggravating factor in NASH.

\section{Materials and Methods}

\section{Animal Experiments}

Protocols used for animal experiments were approved by the Animal Research Committee of Asahikawa Medical University (Asahikawa, Japan). All animal experiments adhered to the criteria outlined in the NIH's Guide for the Care and Use of Laboratory Animals. ${ }^{8}$ All data shown here were obtained from experiments using 8- to 12-week-old male mice (C57BL/6J; Japan SLC, Hamamatsu, Japan). Mice were fed a CDAHFD (A06071302; Research Diets, New Brunswick, NJ) or regular diet for 8 or 12 weeks. To examine acute free radical-mediated liver injury, carbon tetrachloride ( $1 \mathrm{~mL} / \mathrm{kg}$ body weight) was subcutaneously injected, and analysis was performed after 2 days. To induce chronic carbon tetrachloride liver injury with fibrosis, carbon tetrachloride $(1 \mathrm{~mL} / \mathrm{kg}$ body weight) was subcutaneously injected into mice three times per week for 10 weeks, and mice were analyzed 2 days after the last injection. Although the appearance of mice with PSS was not distinct from that of normal mice, histologic examination of the liver readily identified the presence of PSS according to the characteristic features of the portal tract described below. Control mice were selected from the same groups in which mice with PSS were found (PSS-negative littermates).

To examine effects of decreased portal blood flow, in some experiments, partial portal vein ligation (PPVL) was performed with a previously described method, ${ }^{9}$ except a 25 -ga needle was used instead of a 27 -ga needle, because the use of the latter was incompatible with survival in the study mice. As a control, mice were subjected to the same surgical procedures without portal vein ligation. Mice were fed the CDAHFD for 8 weeks and were then analyzed.

In some experiments, pimonidazole hydrochloride $(60$ $\mu \mathrm{g} / \mathrm{g}$ ) was intraperitoneally injected 2 hours before sacrifice to examine levels of tissue oxygenation. Tissue sections were immunostained with an anti-pimonidazole antibody (Hypoxyprobe, Burlington, MA).

\section{Biochemical Analysis of Blood and Tissue Samples}

Plasma alanine aminotransferase (ALT), alkaline phosphatase (ALP), total bilirubin, and total bile acids (TBAs) were measured by routine laboratory methods (Nagahama Life Science Laboratory, Shiga, Japan). Plasma cholesterol and triglyceride levels were measured by Skylight Biotech Inc. (Akita, Japan) using a gel-permeation high-performance liquid chromatography platform (LipoSEARCH, Tokyo, Japan). Levels of triglyceride, total cholesterol, free cholesterol, and phospholipids in liver tissues were also measured by Skylight Biotech Inc. using enzymatic assay kits.

\section{Histologic and Immunohistochemical Analysis}

Livers were fixed in phosphate-buffered $4 \%$ paraformaldehyde for 24 hours at $4{ }^{\circ} \mathrm{C}$, and paraffin sections (4$\mu \mathrm{m}$ thick) were prepared. Paraffin sections were deparaffinized and stained with hematoxylin and eosin. Immunohistochemical staining was performed using an EnVision/HRP system (Dako, Carpinteria, CA) on deparaffinized sections treated with Target Retrieval Solution (Dako). The following antibodies were used: anti-cytokeratin 19 (CK19) (provided by Dr. Atsushi Miyajima, Institute for Quantitative Biosciences, The University of Tokyo, Tokyo, Japan), antifibrinogen (Abcam, Cambridge, UK), anti- $\alpha$-smooth muscle actin ( $\alpha$-SMA) (Proteintech, Rosemont, IL), anti-CYP2E1 (Abcam), anti-8-hydroxyguanine (8-OHdG) (Nikken SEIL, Fukuroi, Japan), anti-connective tissue growth factor (CTGF) (Abcam), anti-pimonidazole (Hypoxyprobe), anti-carbonic anhydrase 9 (CA9) (Proteintech), anti-vascular endothelial cell growth factor (VEGF), antiCD31 (Dianova, Hamburg, Germany), and anti-p62 (Proteintech) antibodies. Chromogen 3,3'-diaminobenzidine tetrahydrochloride was used (Vector Laboratories, Burlingame, CA) for immunohistochemistry. Sections were counterstained with hematoxylin. To evaluate the extent of fibrosis, sections were stained with Sirius Red F3B (Waldeck, Münster, Germany).

Quantitative analyses of immunohistochemistry (fibrinogen, $\alpha$-SMA, CTGF, and CK19) and Sirius Red staining were performed by using ImageJ software version $1.51 \mathrm{n}$ (NIH, Bethesda, MD; https://imagej.nih.gov/ij). The degree of fat accumulation in hepatocytes in mice fed a CDAHFD were analyzed by the image processing integration software WinROOF 2018 (Mitani Corp., Tokyo, Japan). 


\section{Western Blot Analysis}

Protein samples (20 $\mu \mathrm{g}$ per lane) were subjected to SDSPAGE, transferred to polyvinylidene fluoride membranes, and immunoblotted with anti-CYP2E1, anti- $\alpha$-SMA, and anti-GAPDH antibodies. All blots were developed using an enhanced chemiluminescence detection system (GE Healthcare, Chalfont St Giles, UK).

\section{Quantitative RT-PCR}

Total RNA was extracted and subjected to quantitative RTPCR (RT-qPCR) analyses. RT-qPCR was performed using the $\Delta \Delta \mathrm{Ct}$ method with FastStart Universal SYBR Green Master Mix (Roche Diagnostics, Mannheim, Germany). Each reaction was conducted in duplicate, and the mRNA levels were normalized to hypoxanthine phosphoribosyltransferase (Hprt). The primers used in the RT-qPCR experiments are as follows. Acta2: forward, 5'-ACAGC CCTCGCACCCA-3'; reverse, 5'-GCCACCGATCCAGACAGAGT-3'. Hprt: forward, 5'-CCGAGGATTTGGAAA AAGTG-3'; reverse, 5'-CTTATAGCCCCCCTTGAGC-3'

\section{In Vivo Hepatocyte Lineage Tracing}

To genetically label hepatocytes, ROSA26R mice (provided by Dr. Philippe Soriano, Fred Hutchinson Cancer Research Center, Seattle, WA) were infected with adeno-associated virus serotype 8 (AAV8) expressing Cre recombinase under the control of a hepatocyte-specific thyroxine-binding globulin promoter (AAV8-TBG-Cre). All plasmids were obtained from the Penn Vector Core, University of Pennsylvania, PA. ROSA26R mice were injected with $3 \times 10^{10}$ copies of AAV8-TBG-Cre via the lateral tail vein. One week later, a CDAHFD was started. The liver was fixed with $4 \%$ paraformaldehyde and then soaked in $30 \%$ sucrose overnight at $4{ }^{\circ} \mathrm{C}$. Frozen sections were allowed to react with $\mathrm{X}$-gal solution $[1 \mathrm{mg} / \mathrm{mL}$ 5-bromo-4-chloro-3-indolyl- $\beta$-Dgalactopyranoside (X-gal; Sigma-Aldrich, St. Louis, MO), 5 $\mathrm{mmol} / \mathrm{L}$ potassium ferrocyanide, and $5 \mathrm{mmol} / \mathrm{L}$ potassium ferricyanide] at $37^{\circ} \mathrm{C}$ overnight. X-gal-stained sections were then subjected to CK19 immunohistochemistry to examine ductular reaction.

\section{Statistical Analysis}

All data are presented as means \pm SEM. Statistical analyses were performed using an unpaired two-tailed $t$-test, one-way analysis of variance, or two-way analysis of variance, as indicated in each figure legend. $P<0.05$ was considered statistically significant.

\section{Results}

Gross and Microscopic Features of the Liver in Mice with PSS

In mice with PSS, the liver surfaces demonstrated faint nodularity, and edges of the liver were dull, which differed from PSS-free normal livers with smooth surfaces and sharp edges (Figure 1A). Infusion of India ink into the portal vein of normal mice led to the perfusion and blackening of the whole liver; by contrast, in mice with PSS, infused ink barely perfused the liver and directly flowed into the inferior vena cava (Figure 1B). Histologic examination of serial sections of the liver confirmed the connection between the portal vein and inferior vena cava via a shunt vessel, which represents a patent ductus venosus (Figure 1C). In Glisson's sheath of the liver of mice with PSS, portal veins were inconspicuous, but large and thickened hepatic arteries with abundant surrounding connective tissue were present (Figure 1D). In mice with PSS, CK19-positive bile ductular cells, which normally abutted the portal tract, extended to the liver lobule (Figure 1D). Although only male mice were used in the present study, PSS was also found in female mice, whose histologic features were similar to those in male mice (Supplemental Figure S1).

\section{Amelioration of Carbon Tetrachloride-Induced Liver Injury by PSS}

In control mice, a single injection of carbon tetrachloride induced extensive centrilobular necrosis with fibrin deposition, which was highlighted by fibrinogen immunohistochemistry and associated with the myofibroblastic transdifferentiation (activation) of hepatic stellate cells (HSCs) (Figure 2A). However, in mice with PSS, the extent of either the injury or activation of HSCs was reduced compared with that of control mice (Figure 2A). Quantitative analyses of fibrinogen and $\alpha$-SMA immunohistochemistry confirmed the significant amelioration of carbon tetrachloride injury in mice with PSS (Figure 2B). Compatible with the histologic findings, levels of plasma ALT were significantly lower in mice with PSS, whereas levels of ALP and total bilirubin were comparable between the control and PSS groups (Figure 2C). Carbon tetrachloride is known to be hepatocytotoxic due to its activation through metabolization by CYP2E1 to the trichloromethyl radical. ${ }^{10}$ To examine whether PSS decreases CYP2E1 expression in centrilobular hepatocytes, immunohistochemical analyses of CYP2E1 were performed. Although CYP2E1 was predominantly expressed in hepatocytes in the centrilobular area in both normal mice and those with PSS, the staining intensity was stronger in mice with PSS (Figure 2D), which was confirmed by Western blot analysis (Figure 2E), suggesting that the reduction in carbon tetrachloride-induced tissue damage in mice with PSS could not be explained by decreased carbon tetrachloride metabolism. However, 8-OHdG 
A
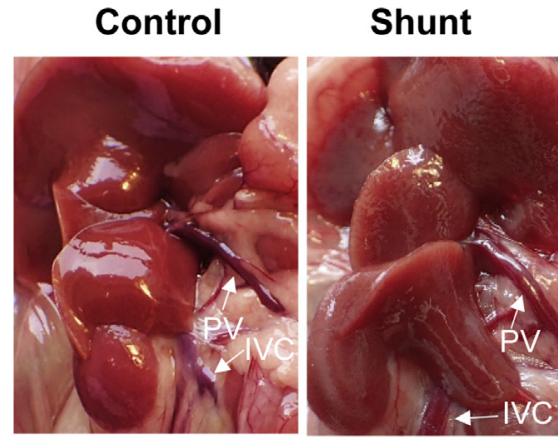

B Control

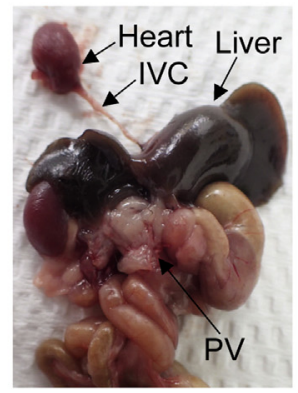

Shunt

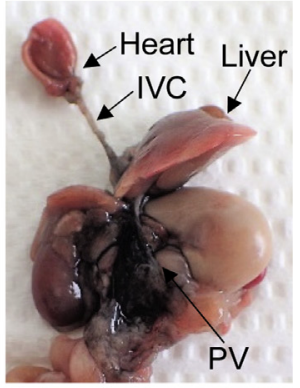

C
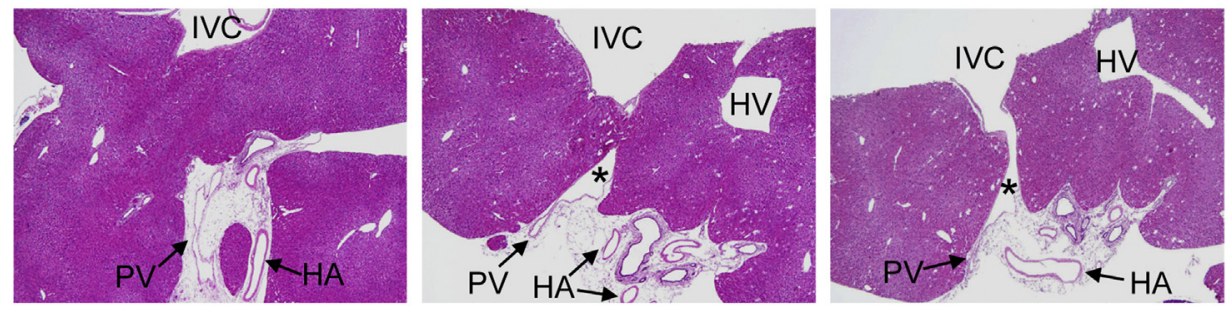

D
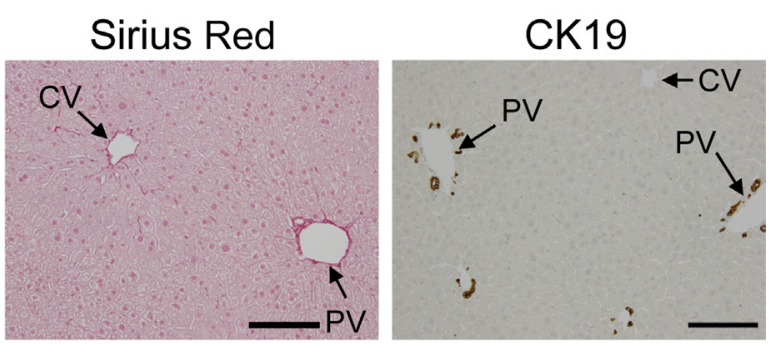

Control
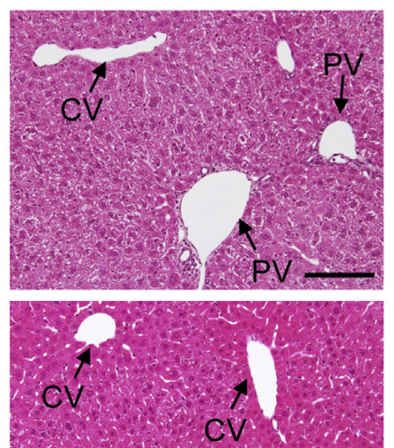

Shunt
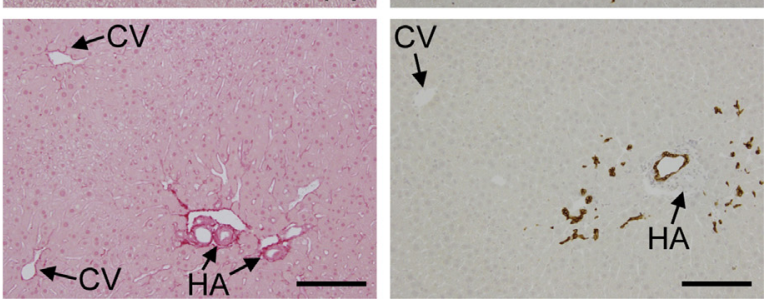

Figure 1 Gross and histologic features of portosystemic shunt (PSS) in C57BL/6J mice. A: Gross appearance of the liver hilum of control and PSS-harboring mice. Shunt: PSS. B: Macroscopic image after the infusion of India ink through the portal vein. Although the ink perfuses the liver in control mice, it enters the IVC and overflows from the cut site of the IVC in PSS-harboring mice. A small amount of ink can be seen in the thoracic IVC. C: Stepwise sectioning of a liver with PSS, obtained with a $4 \times$ objective. There is a direct connection between the PV and IVC via the patent ductus venosus (asterisks). Hematoxylin and eosin (HE) staining. D: Histologic features of a liver with PSS, including an inconspicuous PV, a large and thick HA, and increased bile ductules. HE staining, Sirius Red staining, and cytokeratin 19 (CK19) immunohistochemistry. Scale bars $=100 \mu \mathrm{m}$ (D). CV, central vein; HA, hepatic artery; IVC, inferior vena cava; PV, portal vein.

immunohistochemistry demonstrated that the presence of PSS decreased the levels of its immunoreactivity in the damaged area, indicating that the disturbance of portal blood flow suppresses oxidative stress (Supplemental Figure S2).

In control mice, repeated carbon tetrachloride administration for 10 weeks induced the marked centrilobular fibrosis of the liver, in which increased numbers of $\alpha$-SMA-positive activated HSCs and CK19-positive bile ductules were noted (Figure 2E). As expected, in mice with PSS, the degree of fibrosis, as well as that of HSC activation and ductular reaction, was much lower than in control mice (Figure 2F). These results demonstrate that PSS-induced circulatory disturbance can ameliorate the outcome of free radical-induced liver injury.
Aggravation of NASH-Associated Liver Fibrosis in Mice with PSS

Next, the study examined whether PSS affects the pathology of NASH induced by a CDAHFD. Plasma cholesterol and triglyceride levels were significantly lower in PSS-harboring mice than in control mice, and a CDAHFD decreased levels of plasma cholesterol irrespective of the presence of PSS (Supplemental Figure S3). A CDAHFD markedly increased triglyceride contents of the liver either in control and PSS-harboring mice (Supplemental Figure S4). Because there were interlobular differences, albeit at low levels, in the extent of NASH pathology, the same lobe (left lower lobe) was analyzed to 
A

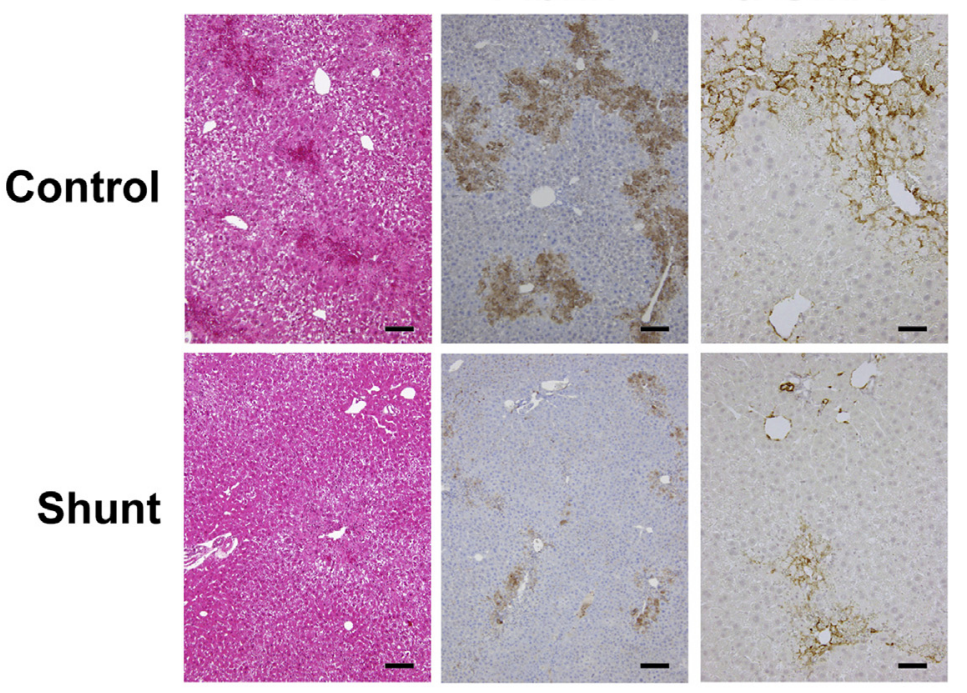

B
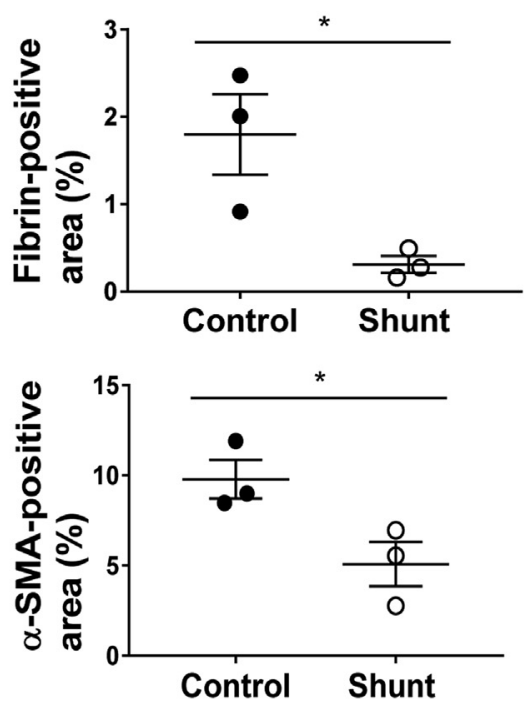

C

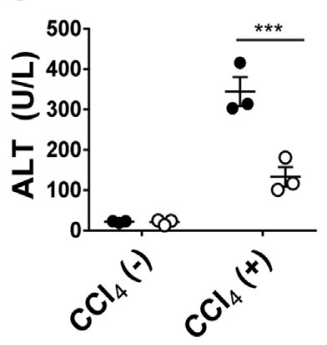

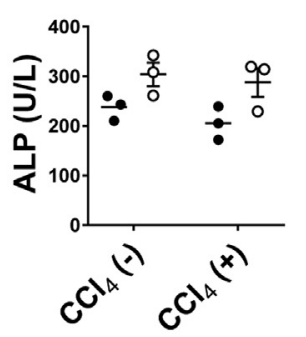

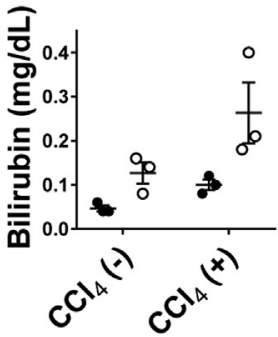

D

\section{CYP2E1}

Control

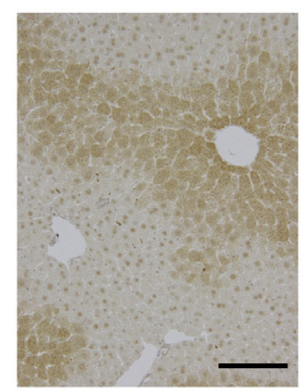

\section{Shunt}

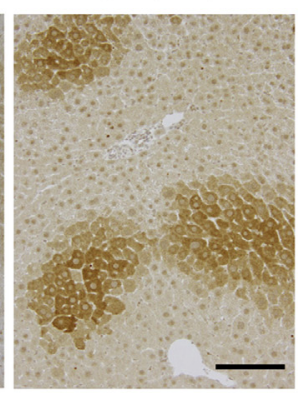

E

\section{Control Shunt}
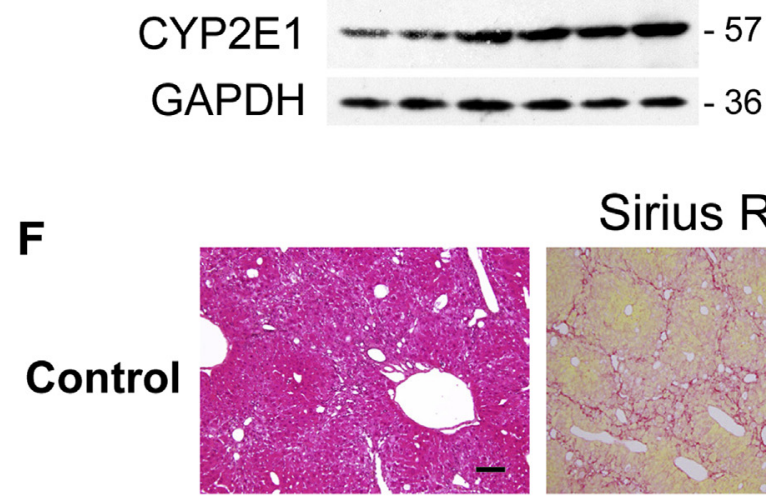

Sirius Red

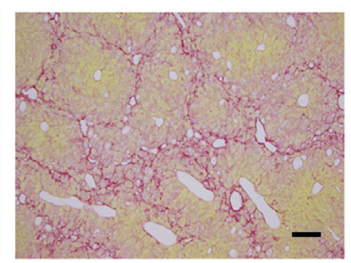

a-SMA

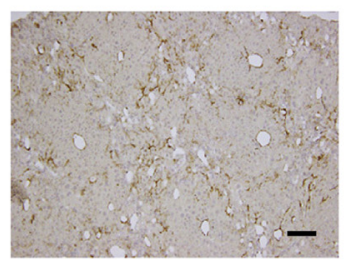

CK19
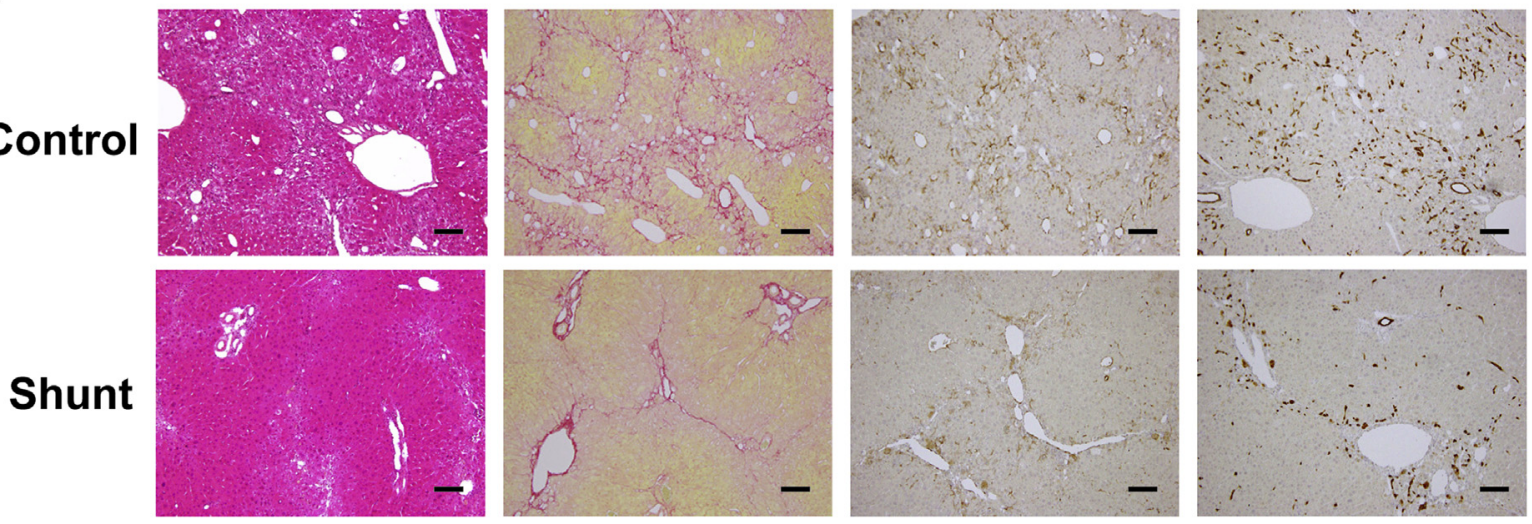

Figure 2 Effects of portosystemic shunt (PSS) on acute and chronic liver injuries induced by carbon tetrachloride. A: Histology of livers 2 days after carbon tetrachloride injury. Hematoxylin and eosin (HE) staining, and fibrinogen and $\alpha$-SMA immunohistochemistry. B: Quantification of fibrinogen (fibrin)-positive and $\alpha$-SMA-positive areas. C: Plasma levels of alanine aminotransferase (ALT), alkaline phosphatase (ALP), and bilirubin. Closed circles: control mice; open circles: shunt (PSS-harboring) mice. D: CYP2E1 immunohistochemistry of intact livers of control and PSS-harboring mice. E: Western blot analysis of CYP2E1 in intact livers of control and PSS-harboring mice. F: Histology of livers after 8 weeks of repetitive carbon tetrachloride injury. HE staining, Sirius Red staining, and $\alpha$-SMA and cytokeratin 19 (CK19) immunohistochemistry. Statistical analysis: $t$-test (B) and two-way analysis of variance (C). $n=3$ for each area (B); $n=3$ for each test (C). ${ }^{*} P<0.05,{ }^{* *} P<0.001$. Scale bars $=100 \mu \mathrm{m}(\mathbf{A}, \mathbf{D}$, and $\mathbf{E})$. 
ensure accurate analyses (Supplemental Figure S5). In control mice, fat accumulation occurred in periportal (zone 1) hepatocytes after 1 week, progressed and diffusely involved panlobular hepatocytes after 4 weeks, and finally affected predominantly centrilobular (zone 3) hepatocytes after 8 weeks (Figure 3A). By contrast, in mice with PSS, fat accumulation was predominant in centrilobular hepatocytes from the beginning (Figure 3A). Although plasma levels of ALT were similar between control and PSSharboring mice, levels of ALP and total bilirubin were significantly higher in the latter (Figure 3B). Plasma levels of TBA were elevated in mice with PSS, regardless of whether they received a regular diet or a CDAHFD (Figure 3C), probably reflecting reduced bile acid uptake by the liver. Although the degree of fat accumulation in the liver in mice with PSS was similar to that in control mice (Figure 3D), pericellular fibrosis, which was predominantly centrilobular, was more prominent in mice with PSS and progressed with time (Figure 3E). The quantification of Sirius Red staining intensity in zones 2 and 3 revealed significant differences between mice with or without PSS (Figure 3F). Both control mice and those with PSS fed a CDAHFD for 12 weeks demonstrated progressed fibrosis, which was more profound in PSS-harboring mice in all hepatic lobes examined (Supplemental Figure S5).

\section{Enhancement of NASH-Associated CTGF Expression and Ductular Reaction by PSS}

In contrast to liver fibrosis induced by chronic carbon tetrachloride injury, in CDAHFD-induced NASH, the expression of $\alpha$-SMA in HSCs was very weak and restricted to cells surrounding dead hepatocytes, without any differences between control mice and PSS-harboring mice (Figure 4A). RT-qPCR and Western blot analysis confirmed that the expression of the $\alpha$-SMA gene (Acta2) and its product was comparable in NASH livers of control mice and PSS-harboring mice (Supplemental Figure S6). However, pericellular fibrosis was associated with CTGF expression in fat-laden hepatocytes, which was markedly enhanced by PSS (Figure 4, A and B). Liver fibrosis in NASH was associated with marked ductular reaction, and the increased CK19-positive ductules originated from existing bile ductules that were proliferating and migrating toward centrilobular areas, because they were negative for X-gal in the hepatocyte lineage-tracing system (Figure 4C). The extent of ductular reaction was significantly higher in mice with PSS than in control mice (Figure 4, D and E).

\section{Effect of PSS on 0xygenation of the Liver Parenchyma}

Tissue hypoxia might be an important contributor to centrilobular ductular reaction with fibrosis. ${ }^{11}$ To examine the consequence of diminished portal circulation and concomitant hepatic arterial buffer response (HABR) with respect to tissue oxygenation, pimonidazole immunohistochemistry of liver tissues was performed in mice that were intraperitoneally administered pimonidazole 2 hours before sacrifice. In control mice, all hepatic lobules were weakly positive for pimonidazole, indicating a diffuse, low-level hypoxic state (Figure 5). By contrast, livers of mice with PSS demonstrated a heterogeneous staining pattern with almost negative staining in zone 1 but very strong staining in zone 3 (Figure 5), suggesting that hyperoxia caused by increased arterial perfusion is limited and that the centrilobular area is rather hypoxic compared with the normal liver. In mice fed a CDAHFD for 8 weeks, fat-laden hepatocytes showed intense pimonidazole staining, but the staining intensity was higher in mice with PSS (Figure 5). Immunohistochemistry for CA9, a hypoxia marker, revealed that its expression was higher in NASH livers and further augmented by PSS (Figure 5). VEGF, which is known to be induced by hypoxia, became positive in fat-laden hepatocytes in NASH, whereas VEGF expression levels were particularly high in mice with PSS (Figure 5). In accordance with the robust expression of VEGF, there were numerous small vessels lined by CD31positive endothelial cells in the centrilobular area of livers of NASH mice with PSS (Figure 5). Because compromised autophagic processes have been shown to contribute to the progression of NASH, the authors examined p62 expression, which reflects disrupted autophagy. In NASH livers, p62 was found to be strongly positive in some fat-laden hepatocytes, and the presence of PSS further increased the number of positive hepatocytes and augmented its expression levels (Supplemental Figure S7).

\section{Aggravation of NASH-Associated Liver Fibrosis and Ductular Reaction in Mice Subjected to PPVL}

To examine whether a decrease in portal blood flow aggravates pathological changes associated with NASH, PPVL was performed 2 weeks before beginning a CDAHFD. The extent of fat accumulation, as well as hepatic triglyceride contents, was comparable between control mice and those subjected to PPVL (Figure 6A and Supplemental Figure S4), as were plasma levels of ALT and total bilirubin, although there was a slight decrease in ALP levels in mice with PPVL (Figure 6B). PPVL induced the dilation and thickening of hepatic arteries, suggesting HABR (Figure 6A) and increased plasma levels of TBA (Figure 6C). Pericellular fibrosis in the centrilobular area, as well as ductular reaction, was more marked in mice subjected to PPVL than in control mice (Figure 6A). The quantification of Sirius Red staining and CK19 immunohistochemistry revealed that there were significant differences between control mice and those subjected to PPVL (Figure 6, D and E). 
A

CDAHFD
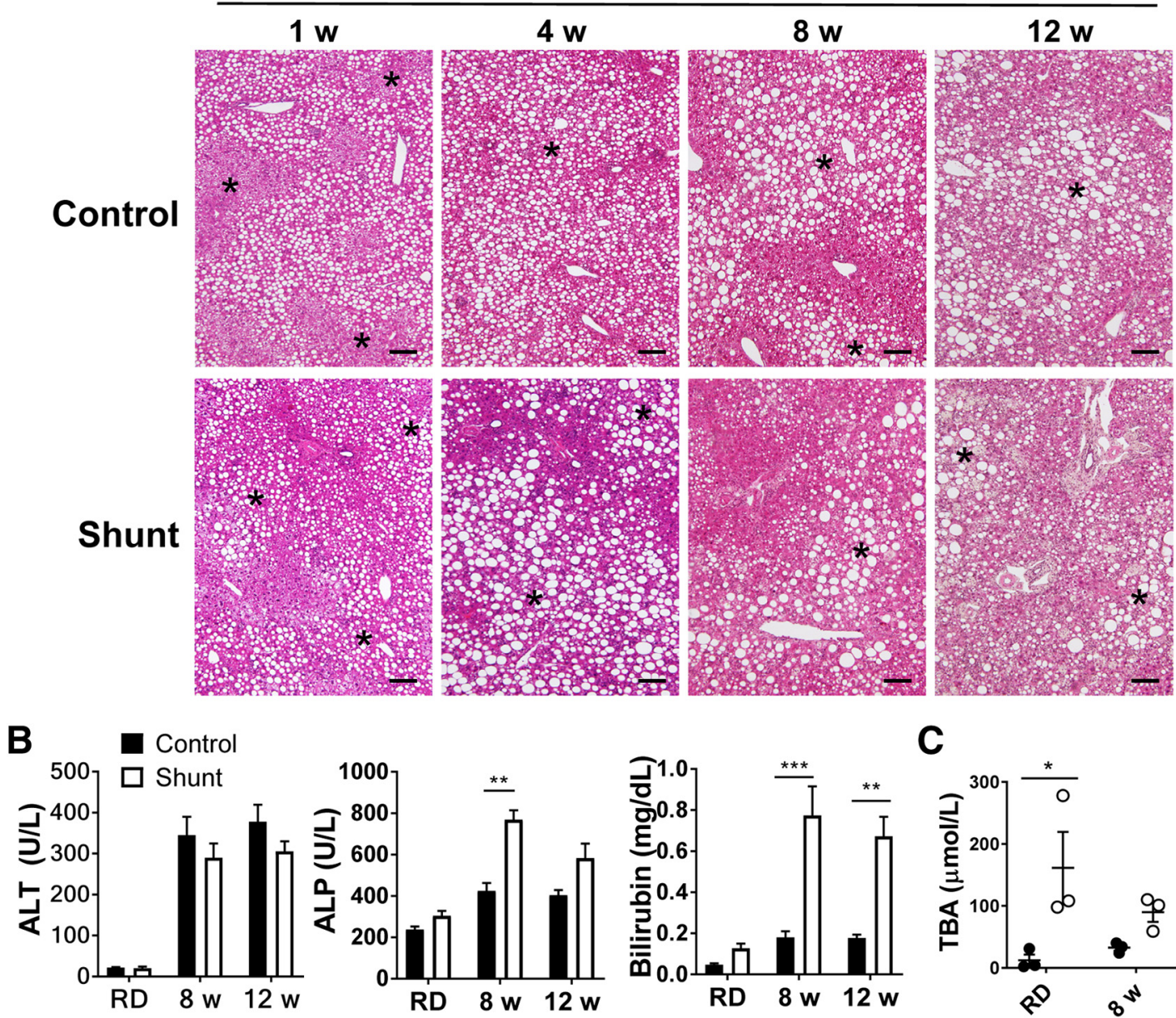

C
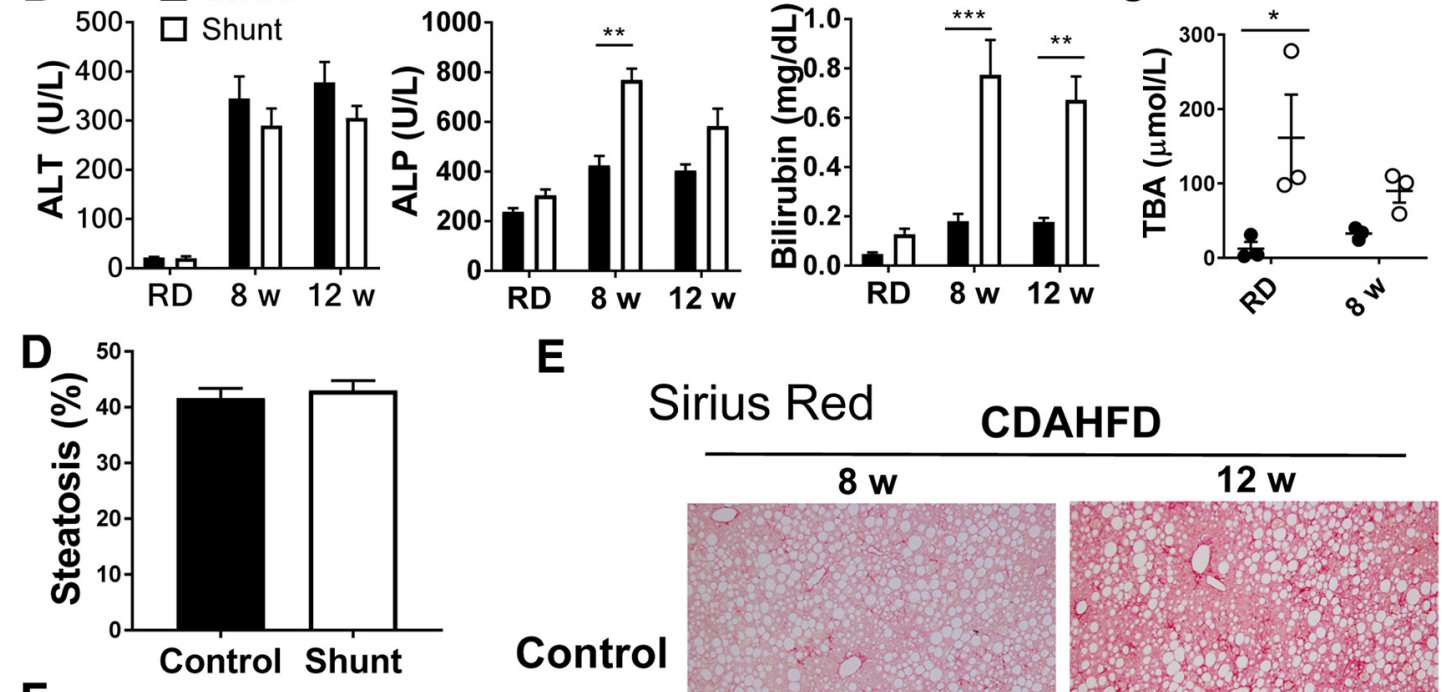

E

\section{Sirius Red CDAHFD}

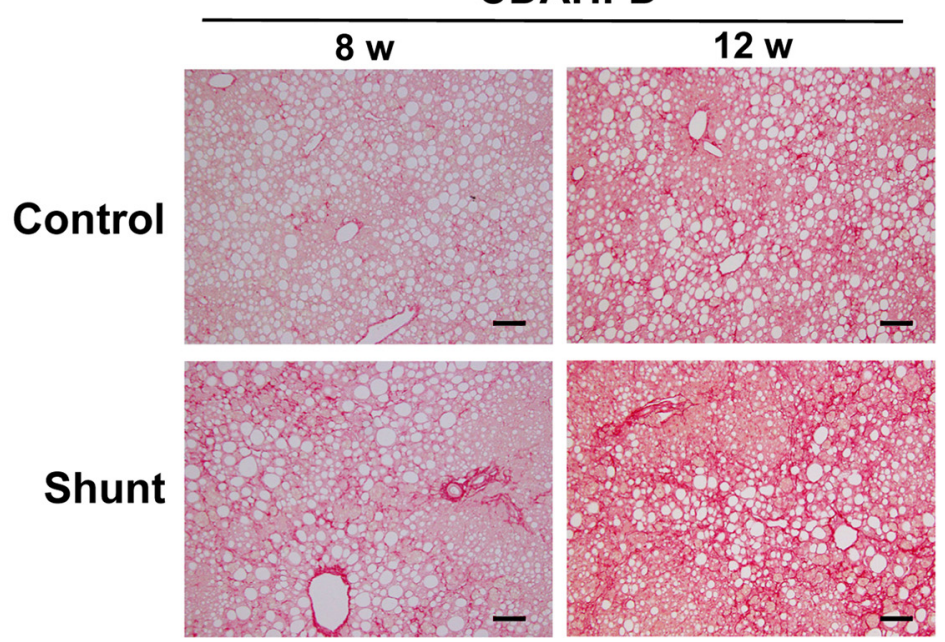

Figure 3 Effects of portosystemic shunt (PSS) on choline-deficient L-amino acid-defined high-fat diet (CDAHFD)-induced nonalcoholic steatohepatitis (NASH). A: Histology of livers in control and PSS-harboring mice fed a CDAHFD for 1 to 12 weeks. Asterisks indicate the centrilobular area (zone 3). Hematoxylin and eosin staining. B: Plasma levels of alanine aminotransferase (ALT), alkaline phosphatase (ALP), and bilirubin. C: Plasma levels of total bile acids (TBA). D: Quantification of steatosis induced by a CDAHFD (8 weeks). E and F: Sirius Red (SR) staining of livers of control and PSS-harboring mice fed a CDAHFD for 8 and 12 weeks (E) and its quantification (F). Statistical analysis: two-way analysis of variance (B and $\mathbf{F}) . n=3$ for each test (B); $n=3(\mathbf{C}$ and $\mathbf{D}) ; n=3$ mice for each condition (E and $\mathbf{F}$ ). ${ }^{*} P<0.05$, ${ }^{* *} P<0.01,{ }^{* *} P<0.001$, and ${ }^{*} * * P<0.0001$. Scale bars $=100 \mu \mathrm{m}(\mathbf{A}$ and $\mathbf{E})$. 
A a-SMA

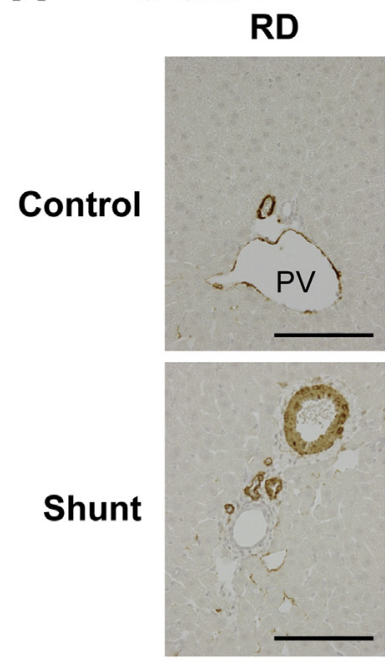

B

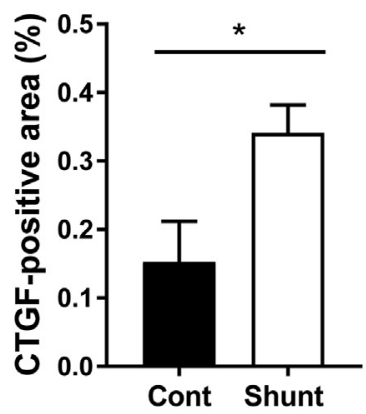

D $\quad$ CK19
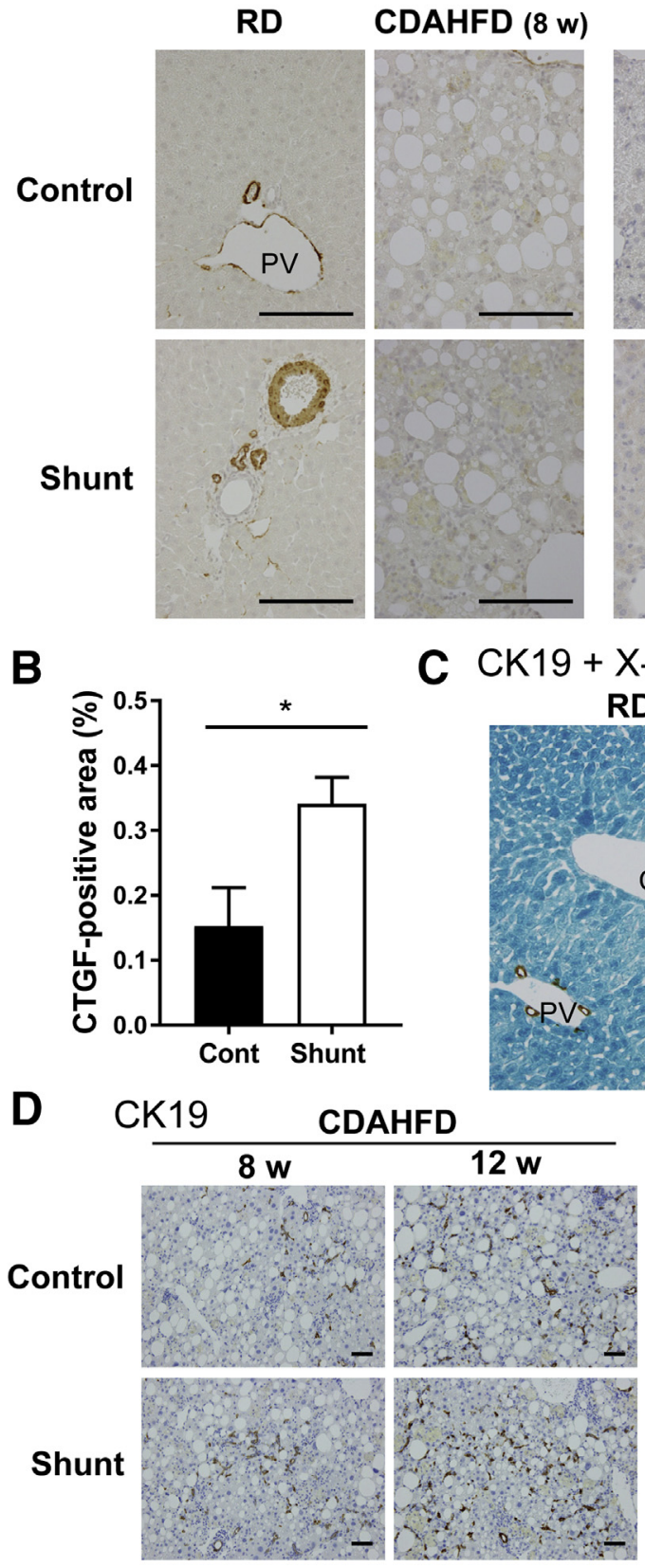

\section{CTGF}

C $\mathrm{CK} 19+\mathrm{X}$-gal
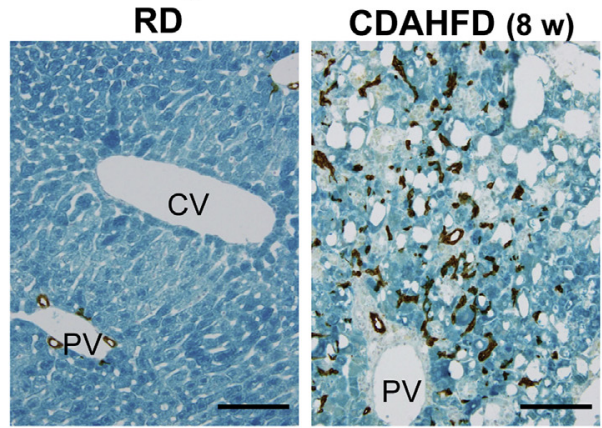

E

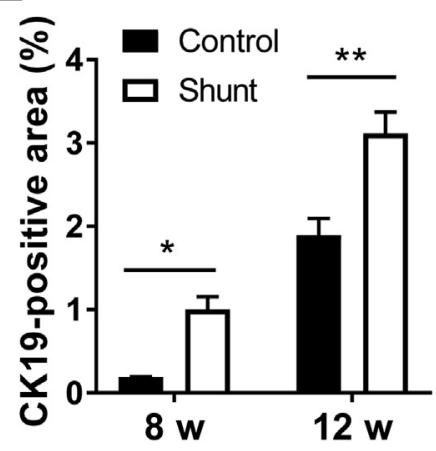

Figure 4 Effects of portosystemic shunt (PSS) on hepatic stellate cell (HSC) activation and ductular reaction in choline-deficient L-amino acid -defined high-fat diet (CDAHFD)-induced nonalcoholic steatohepatitis (NASH). A: Immunohistochemistry for $\alpha$-smooth muscle actin ( $\alpha$-SMA) and connective tissue growth factor (CTGF) in livers of control and PSS-harboring mice fed a regular diet (RD) or a CDAHFD for 8 weeks. B: Quantification of CTGF-positive area in livers of control and PSSharboring mice fed an RD or a CDAHFD for 8 weeks. C: Hepatocyte lineage tracing in livers of mice fed an RD or a CDAHFD for 8 weeks. AAV8TBG-Cre-infected ROSA26R mice. CK19 and X-gal double staining. D and E: CK19 immunohistochemistry of livers of control and PSS-harboring mice fed a CDAHFD for 8 and 12 weeks (D) and its quantification (E). Statistical analysis: $t$-test (B) and two-way analysis of variance (E). $n=3$ mice for each condition ( $\mathbf{D}$ and $\mathbf{E}$ ). ${ }^{*} P<0.05$, ${ }^{* *} P<0.01$. Scale bars $=100 \mu \mathrm{m}(\mathbf{A}, \mathbf{C}$, and D). $\mathrm{CV}$, central vein; PV, portal vein.

\section{Discussion}

The present study demonstrates that decreased portal blood flow associated with PSS in mice aggravated liver fibrosis and ductular reaction in a NASH model but ameliorated liver injury caused by carbon tetrachloride. In PSS, part or all of the portal vein blood flow does not pass through the liver but instead enters the systemic circulation. Congenital PSS, classified as extrahepatic or intrahepatic PSS, is believed to result from the incomplete involution of early embryonic vessels during fetal development or after birth for the ductus venosus. ${ }^{12-15}$ Although congenital
PSS is very rare in humans, various types of PSS are frequently found in dogs. ${ }^{16}$ Interestingly, PSS due to patent ductus venosus is often observed in C57BL/6J mice, but not in $\mathrm{C} 57 \mathrm{BL} / 6 \mathrm{~N}$ mice, another C57BL substrain, or other mouse strains. ${ }^{7}$ This abnormality might be related to the specific genetic background of this particular substrain, such as the homozygous deletion of the nicotinamide nucleotide transhydrogenase (Nnt) gene. ${ }^{17,18}$ The frequency of PSS in C57BL/6J mice was found to be increased in knockouts of several genes, including aryl hydrocarbon receptor $(A h r),{ }^{19}$ nuclear factor erythroid 2-related factor 2 $(N r f 2),{ }^{20}$ and fucosyltransferase 2 (Fut2), ${ }^{21}$ suggesting that 


\section{Pimonidazole}

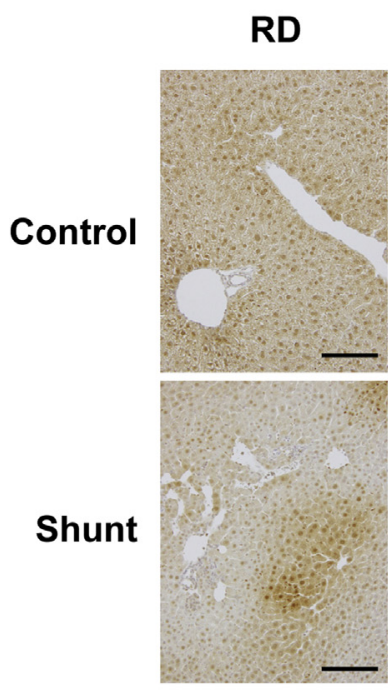

VEGF
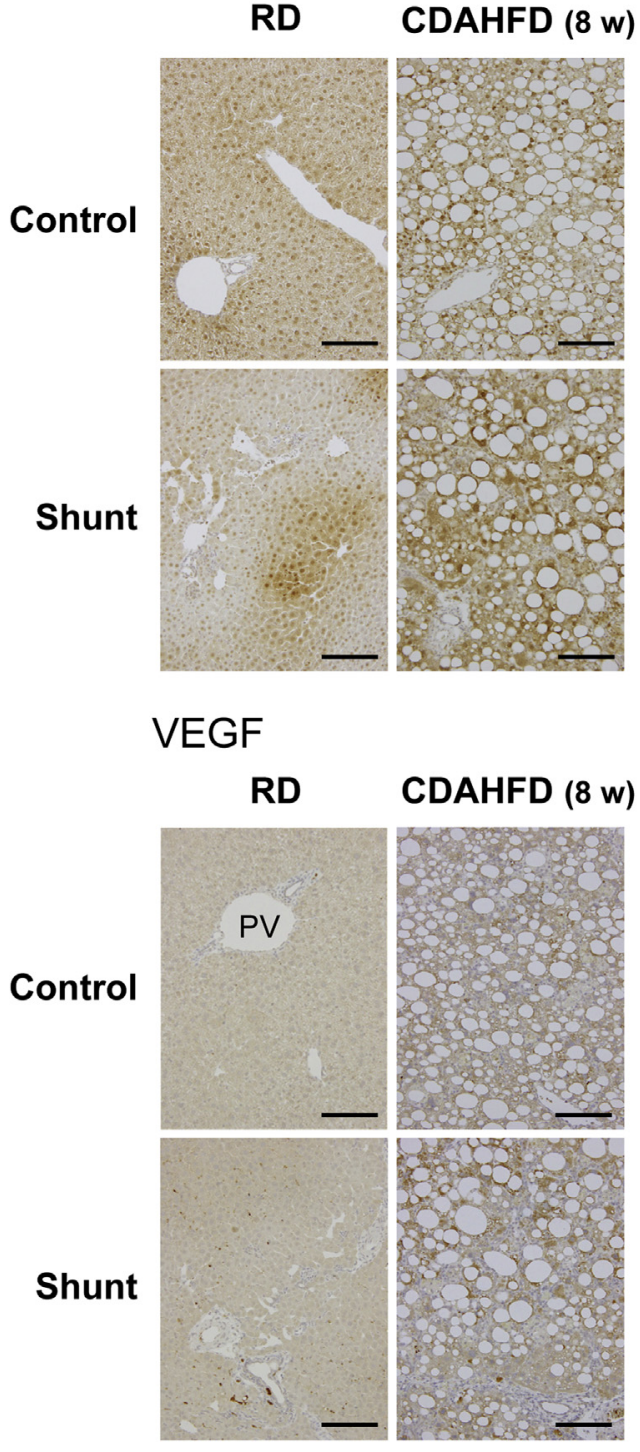

\section{CA9}

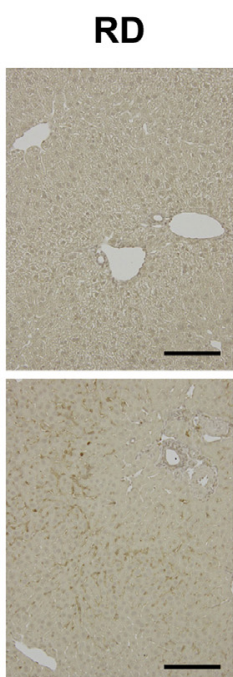

CD31

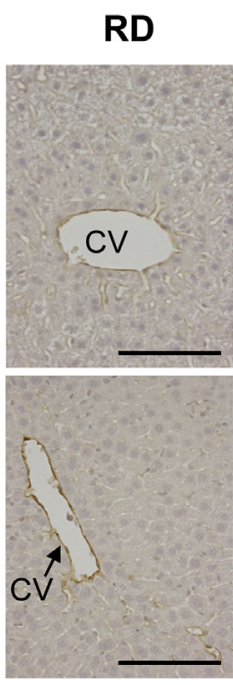

CDAHFD (8 w)

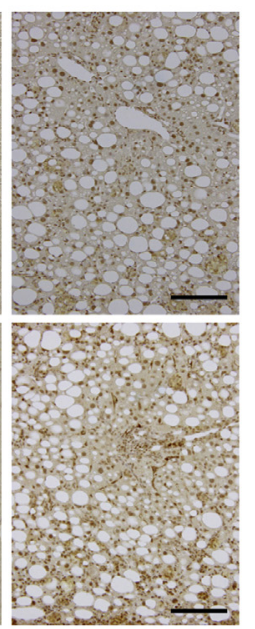

CDAHFD (8 w)

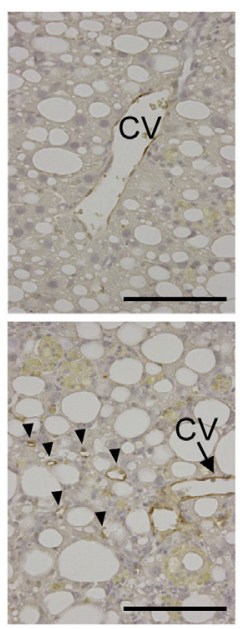

Figure 5 Effects of portosystemic shunt (PSS) on tissue oxygenation, the expression of hypoxic markers, and neovascularization in cholinedeficient L-amino acid-defined high-fat diet (CDAHFD)-induced nonalcoholic steatohepatitis (NASH). Pimonidazole hydrochloride was intraperitoneally injected 2 hours before sacrifice. Immunohistochemistry for pimonidazole, carbonic anhydrase 9 (CA9), vascular endothelial cell growth factor (VEGF), CD31, and connective tissue growth factor (CTGF) in livers of control and PSS-harboring mice fed a CDAHFD for 8 weeks. Arrowheads indicate aberrant CD31-positive vessels within the lobule. Scale bars: $100 \mu \mathrm{m}$. CV, central vein; PV, portal vein; RD, regular diet. the pathogenesis of patent ductus venosus might be multifactorial.

The presence of PSS has been reported to reduce acute liver injury caused by carbon tetrachloride administration due to reduced CYP2E1 expression. ${ }^{20}$ However, our analyses revealed that the expression of CYP2E1 in the centrilobular area was higher in PSS-harboring mice. It has been shown that the trichloromethyl radical generated by CYP2E1 is further converted in the presence of oxygen to the trichloromethylperoxy radical, which is particularly cytotoxic. ${ }^{10}$ Levels of tissue oxygenation in the centrilobular area were significantly lower in PSS-harboring mice than in control mice. Therefore, it is possible that the decreased tissue injury caused by carbon tetrachloride might be due to the low oxygen availability in the area where toxic free radicals are generated. The attenuated 8-OHdG immunoreactivity is compatible with a reduced free radical injury in PSS-harboring mice. Although HABR with the marked enlargement and thickening of hepatic artery walls was associated with PSS, the increased tissue oxygenation was restricted to zone 1 , probably due to the abnormal perfusion of the arterial blood within the hepatic lobule. It has been shown that portal blood consists of $75 \%$ to $80 \%$ of total hepatic blood flow and provides $50 \%$ of total hepatic oxygen demand. ${ }^{22}$ In canine experimental PSS induced by an Eck fistula, total liver blood flow has been reported to be reduced to $53 \%$, even in the presence of a compensatory increase in arterial blood flow. ${ }^{23}$

NAFLD is known to be complicated by portal hypertension from the early stage when liver fibrosis is not discernible. Portal hypertension in noncirrhotic NAFLD is attributed to the steatosis and ballooning of hepatocytes and alterations in nonparenchymal cells. ${ }^{5,6}$ Subsequently, sinusoidal capillarization and HSC activation induce hepatic 


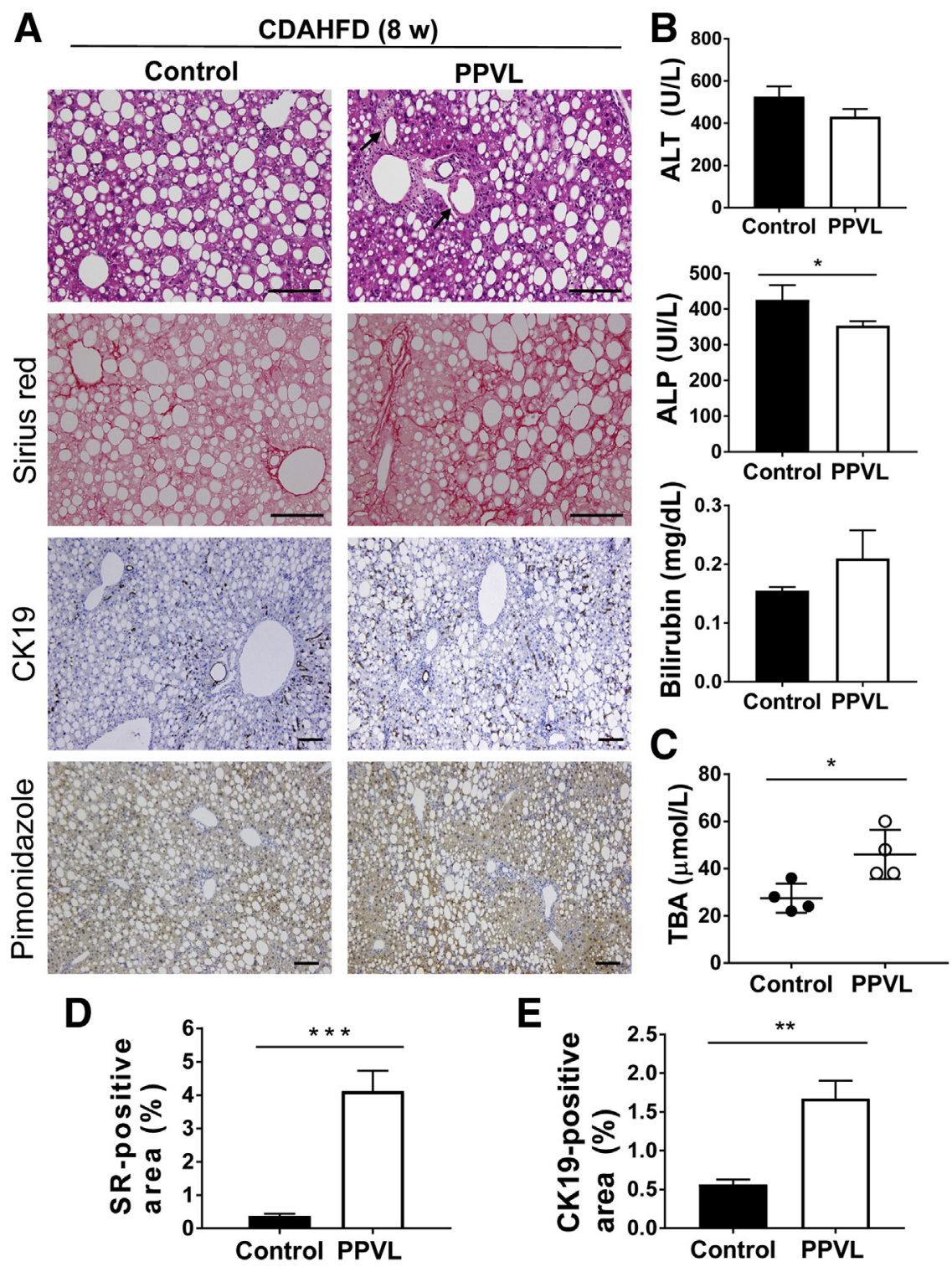

Figure 6 Effects of partial portal vein ligation (PPVL) on liver fibrosis, ductular reaction, and tissue oxygenation in choline-deficient L-amino acid-defined high-fat diet (CDAHFD)-induced nonalcoholic steatohepatitis (NASH). A: Hematoxylin and eosin staining, Sirius Red staining, and immunohistochemistry for CK19 and pimonidazole in livers of control mice and those subjected to PPVL fed a CDAHFD for 8 weeks. Arrows indicate dilated and thickened hepatic arteries in mice with PPVL. B: Plasma levels of alanine aminotransferase (ALT), alkaline phosphatase (ALP), and bilirubin. C: Plasma levels of total bile acids (TBA). D: Quantification of the Sirius Red-positive area. E: Quantification of the CK19-positive area. Statistical analysis: $t$-test (B-E). $n=3$ for each test (B); $n=3$ (C, D, and E). ${ }^{*} P<0.05,{ }^{*} P<0.01$, and ${ }^{* * *} P<0.001$. Scale bars $=100 \mu \mathrm{m}$. hypoxia and collagen deposition in the space of Disse, respectively. Hypoxia induces VEGF expression and causes neovascularization, ${ }^{24,25}$ both of which are associated with pericellular fibrosis in zone $3 .^{26,27}$ The present study demonstrates that NASH induced by a CDAHFD was associated with tissue hypoxia and increased hypoxic marker (CA9 and VEGF) expression, and they were further augmented by PSS. Profound neovascularization with the emergence of intralobular CD31-positive small vessels was also observed in PSS-harboring mice, indicating the presence of a disrupted hemodynamic status. Recently, in a steatotic mouse strain on a high-fat diet, genome-wide linkage analysis identified genes involved in lipophagy. ${ }^{28}$ In fact, p62 was found to be accumulated in steatotic hepatocytes, and it was further increased by PSS in CDAHFD-induced NASH, suggesting that NASH progression is associated with disturbances in autophagy.
Unlike the carbon tetrachloride chronic injury model, which is characterized by tissue repair following parenchymal destruction, few $\alpha$-SMA-positive activated HSCs were observed in pericellular fibrosis in NASH, suggesting that the mechanism of increased collagen production by HSCs is different. CTGF was expressed at high levels in $\mathrm{NASH}$, and PSS further increased its expression. Liver fibrosis has been demonstrated to be dependent on CTGF, ${ }^{29}$ and the authors' findings are in accordance with previous studies showing the possible involvement of CTGF in the progression of fibrosis in experimental NASH models. ${ }^{30,31}$ Importantly, CTGF has been reported to be induced by hypoxia, ${ }^{32,33}$ thus providing a possible pathogenic link between fibrosis and hypoxia in NASH.

Pericellular fibrosis in CDAHFD-induced NASH was accompanied by marked ductular reaction. This ductular reaction has been shown to be correlated with the 
progression of fibrosis and dependent on high dietary fat. ${ }^{34}$ Using hepatocyte lineage-tracing systems in mice, the authors previously reported that although both hepatocytes and bile ductular cells could be the cells of origin of increased bile ductular cells in chronic liver injury induced by carbon tetrachloride or other liver toxins, the major part of ductular reaction is ascribed to the robust remodeling of the bile ductular system, that is, the proliferation and migration of existing bile ductular cells. ${ }^{35}$ The present study demonstrates that ductular reaction in NASH occurs almost exclusively due to the proliferation and centrilobular migration of bile ductules. It has been hypothesized that centrilobular ductular reaction (type 2B) might be induced by tissue hypoxia. ${ }^{11}$ Furthermore, ductular reaction in an experimental NASH model has been associated with the activation of $\mathrm{YAP}^{36}$ which positively regulates the expression of CTGF. ${ }^{37}$ Interestingly, the inhibition of YAP by a genetic recombination approach has been demonstrated to compromise the survival of mice fed a choline-deficient methionine-supplemented diet, which induces a NASHlike state, ${ }^{38}$ suggesting that ductular reaction in NASH might be an adaptive response.

PPVL significantly aggravated liver fibrosis and enhanced ductular reaction. PPVL induced HABR, but levels of tissue oxygenation were lower than those in control mice, suggesting a state of disrupted intralobular circulation. These findings further support the hypothesis that decreased portal circulation is involved in the progression of NAFLD. Importantly, various levels of decreased portal circulation is a general feature of chronic liver diseases with portal hypertension, and HABR in response to decreased portal venous perfusion has been shown to be maintained even in advanced cirrhosis. ${ }^{39}$ Prior to the development of cirrhosis in NASH livers, arteries originating from the portal tract are found to reach the fibrotic area around the central vein and hepatic vein, ${ }^{26,27}$ suggesting that these aberrant arteries might represent anatomic features of HABR. Patients with NAFLD with HABR are associated with higher hepatic fibrosis scores and more prone to developing metabolic diseases than patients with NAFLD without HABR. ${ }^{40}$

In conclusion, the present study provides the first experimental evidence showing that decreased portal blood perfusion is an important factor in the progression of NAFLD. We propose that tissue hypoxia induced by disrupted hepatic circulation accelerates liver fibrosis with ductular reaction, although there might be contributions of the decreased availability of portal soluble factors, including those produced by the gut microbiome. It is likely that a vicious cycle may develop in which decreased portal blood perfusion induces liver fibrosis that further hampers hepatic circulation.

\section{Acknowledgments}

We thank Prof. Yukio Nagasaki (University of Tsukuba, Japan) for his suggestions and support, Yoshiyasu Satake for assistance with animal care, and Aya Kitano for administrative assistance.

\section{Supplemental Data}

Supplemental material for this article can be found at http://doi.org/10.1016/j.ajpath.2021.06.001.

\section{References}

1. Loomba R, Wong R, Fraysse J, Shreay S, Li S, Harrison S, Gordon SC: Nonalcoholic fatty liver disease progression rates to cirrhosis and progression of cirrhosis to decompensation and mortality: a real world analysis of Medicare data. Aliment Pharmacol Ther 2020, 51:1149-1159

2. Younossi Z, Stepanova M, Sanyal AJ, Harrison SA, Ratziu V, Abdelmalek MF, Diehl AM, Caldwell S, Shiffman ML, Schall RA, McColgan B, Subramanian GM, Myers RP, Muir A, Afdhal NH, Bosch J, Goodman Z: The conundrum of cryptogenic cirrhosis: adverse outcomes without treatment options. J Hepatol 2018, 69:1365-1370

3. Negro F: Natural history of NASH and HCC. Liver Int 2020, 40(Supp1 1):72-76

4. Takahashi H, Suzuki M, Ikeda H, Kobayashi M, Sase S, Yotsuyanagi H, Maeyama S, Iino S, Itoh F: Evaluation of quantitative portal venous, hepatic arterial, and total hepatic tissue blood flow using xenon CT in alcoholic liver cirrhosis-comparison with liver cirrhosis related to hepatitis $\mathrm{C}$ virus and nonalcoholic steatohepatitis. Alcohol Clin Exp Res 2010, 34(Suppl 1):S7-S13

5. Baffy G: Origins of portal hypertension in nonalcoholic fatty liver disease. Dig Dis Sci 2018, 63:563-576

6. Hirooka M, Koizumi Y, Miyake T, Ochi H, Tokumoto Y, Tada F, Matsuura B, Abe M, Hiasa Y: Nonalcoholic fatty liver disease: portal hypertension due to outflow block in patients without cirrhosis. Radiology 2015, 274:597-604

7. Cudalbu C, McLin VA, Lei H, Duarte JM, Rougemont AL, Oldani G, Terraz S, Toso C, Gruetter R: The C57BL/6J mouse exhibits sporadic congenital portosystemic shunts. PLoS One 2013, 8:e69782

8. Committee for the Update of the Guide for the Care and Use of Laboratory Animals; National Research Council: Guide for the Care and Use of Laboratory Animals. Eighth Edition. Washington, DC, National Academies Press, 2011

9. Iwakiri Y, Cadelina G, Sessa WC, Groszmann RJ: Mice with targeted deletion of eNOS develop hyperdynamic circulation associated with portal hypertension. Am J Physiol Gastrointest Liver Physiol 2002, 283:G1074-G1081

10. Weber LW, Boll M, Stampfl A: Hepatotoxicity and mechanism of action of haloalkanes: carbon tetrachloride as a toxicological model. Crit Rev Toxicol 2003, 33:105-136

11. Desmet VJ: Ductal plates in hepatic ductular reactions. Hypothesis and implications. I. Types of ductular reaction reconsidered. Virchows Arch 2011, 458:251-259

12. Franchi-Abella S, Gonzales E, Ackermann O, Branchereau S, Pariente D, Guerin F: Congenital portosystemic shunts: diagnosis and treatment. Abdom Radiol (NY) 2018, 43:2023-2036

13. Papamichail M, Pizanias M, Heaton N: Congenital portosystemic venous shunt. Eur J Pediatr 2018, 177:285-294

14. Guerra A, De Gaetano AM, Infante A, Mele C, Marini MG, Rinninella E, Inchingolo R, Bonomo L: Imaging assessment of portal venous system: pictorial essay of normal anatomy, anatomic variants and congenital anomalies. Eur Rev Med Pharmacol Sci 2017, 21: 4477-4486

15. Baiges A, Turon F, Simón-Talero M, Tasayco S, Bueno J, Zekrini K, et al: Congenital extrahepatic portosystemic shunts (Abernethy 
malformation): an international observational study. Hepatology 2020, 71:658-669

16. Van den Bossche L, van Steenbeek FG: Canine congenital portosystemic shunts: disconnections dissected. Vet J 2016, 211:14-20

17. Mekada K, Abe K, Murakami A, Nakamura S, Nakata H, Moriwaki K, Obata Y, Yoshiki A: Genetic differences among C57BL/6 substrains. Exp Anim 2009, 58:141-149

18. Kraev A: Parallel universes of Black Six biology. Biol Direct 2014, 9:18

19. Lahvis GP, Lindell SL, Thomas RS, McCuskey RS, Murphy C, Glover E, Bentz M, Southard J, Bradfield CA: Portosystemic shunting and persistent fetal vascular structures in aryl hydrocarbon receptor-deficient mice. Proc Natl Acad Sci U S A 2000, 97: 10442-10447

20. Skoko JJ, Wakabayashi N, Noda K, Kimura S, Tobita K, Shigemura N, Tsujita T, Yamamoto M, Kensler TW: Loss of Nrf2 in mice evokes a congenital intrahepatic shunt that alters hepatic oxygen and protein expression gradients and toxicity. Toxicol Sci 2014, 141: $112-119$

21. Maroni L, Hohenester SD, van de Graaf SFJ, Tolenaars D, van Lienden K, Verheij J, Marzioni M, Karlsen TH, Oude Elferink RPJ, Beuers U: Knockout of the primary sclerosing cholangitis-risk gene Fut2 causes liver disease in mice. Hepatology 2017, 66:542-554

22. Payne JT, Martin RA, Constantinescu GM: The anatomy and embryology of portosystemic shunts in dogs and cats. Semin Vet Med Surg Small Anim 1990, 5:76-82

23. Ackroyd FW, Mito M, McDermott WV Jr: Autonomic vasomotor controls in hepatic blood flow. Am J Surg 1966, 112:356-362

24. Coulon S, Legry V, Heindryckx F, Van Steenkiste C, Casteleyn C, Olievier K, Libbrecht L, Carmeliet P, Jonckx B, Stassen J-M, Van Vlierberghe H, Leclercq I, Colle I, Geerts A: Role of vascular endothelial growth factor in the pathophysiology of nonalcoholic steatohepatitis in two rodent models. Hepatology 2013, 57: $1793-1805$

25. Iwakiri Y, Shah V, Rockey DC: Vascular pathobiology in chronic liver disease and cirrhosis - current status and future directions. J Hepatol 2014, 61:912-924

26. Gill RM, Belt P, Wilson L, Bass NM, Ferrell LD: Centrizonal arteries and microvessels in nonalcoholic steatohepatitis. Am J Surg Pathol 2011, 35:1400-1404

27. Hano H, Takasaki S, Kobayashi H, Koyama T, Lu T, Nagatsuma K: In the non-cirrhotic stage of nonalcoholic steatohepatitis, angioarchitecture of portal veins and lobular architecture are maintained. Virchows Arch 2013, 462:533-540

28. Schwerbel K, Kamitz A, Krahmer N, Hallahan N, Jahnert M, Gottmann P, Lebek S, Schallschmidt T, Arends D, Schumacher F, Kleuser B, Haltenhof T, Heyd F, Gancheva S, Broman KW, Roden M, Joost HG, Chadt A, Al-Hasani H, Vogel H, Jonas W, Schurmann A: Immunity-related GTPase induces lipophagy to prevent excess hepatic lipid accumulation. J Hepatol 2020, 73:771-782

29. Pi L, Robinson PM, Jorgensen M, Oh SH, Brown AR, Weinreb PH, Trinh TL, Yianni P, Liu C, Leask A, Violette SM,
Scott EW, Schultz GS, Petersen BE: Connective tissue growth factor and integrin alphavbeta6: a new pair of regulators critical for ductular reaction and biliary fibrosis in mice. Hepatology 2015, 61:678-691

30. Paradis V, Perlemuter G, Bonvoust F, Dargere D, Parfait B, Vidaud M, Conti M, Huet S, Ba N, Buffet C, Bedossa P: High glucose and hyperinsulinemia stimulate connective tissue growth factor expression: a potential mechanism involved in progression to fibrosis in nonalcoholic steatohepatitis. Hepatology 2001, 34: 738-744

31. Sato W, Horie Y, Kataoka E, Ohshima S, Dohmen T, Iizuka M, Sasaki J, Sasaki T, Hamada K, Kishimoto H, Suzuki A, Watanabe S: Hepatic gene expression in hepatocyte-specific Pten deficient mice showing steatohepatitis without ethanol challenge. Hepatol Res 2006, $34: 256-265$

32. Shimo T, Kubota S, Kondo S, Nakanishi T, Sasaki A, Mese H, Matsumura T, Takigawa M: Connective tissue growth factor as a major angiogenic agent that is induced by hypoxia in a human breast cancer cell line. Cancer Lett 2001, 174:57-64

33. Higgins DF, Biju MP, Akai Y, Wutz A, Johnson RS, Haase VH: Hypoxic induction of Ctgf is directly mediated by Hif-1. Am J Physiol Renal Physiol 2004, 287:F1223-F1232

34. Wei G, An P, Vaid KA, Nasser I, Huang P, Tan L, Zhao S, Schuppan D, Popov YV: Comparison of murine steatohepatitis models identifies a dietary intervention with robust fibrosis, ductular reaction, and rapid progression to cirrhosis and cancer. Am J Physiol Gastrointest Liver Physiol 2020, 318:G174-G188

35. Nagahama $Y$, Sone $M$, Chen X, Okada Y, Yamamoto M, Xin B, Matsuo Y, Komatsu M, Suzuki A, Enomoto K, Nishikawa Y: Contributions of hepatocytes and bile ductular cells in ductular reactions and remodeling of the biliary system after chronic liver injury. Am J Pathol 2014, 184:3001-3012

36. Machado MV, Michelotti GA, Pereira TA, Xie G, Premont R, Cortez-Pinto H, Diehl AM: Accumulation of duct cells with activated YAP parallels fibrosis progression in non-alcoholic fatty liver disease. J Hepatol 2015, 63:962-970

37. Zhao B, Ye X, Yu J, Li L, Li W, Li S, Yu J, Lin JD, Wang C-Y, Chinnaiyan AM, Lai Z-C, Guan K-L: TEAD mediates YAPdependent gene induction and growth control. Genes Dev 2008, 22: $1962-1971$

38. Planas-Paz L, Sun T, Pikiolek M, Cochran NR, Bergling S, Orsini V, et al: YAP, but not RSPO-LGR4/5, signaling in biliary epithelial cells promotes a ductular reaction in response to liver injury. Cell Stem Cell 2019, 25:39-53.e10

39. Gulberg V, Haag K, Rossle M, Gerbes AL: Hepatic arterial buffer response in patients with advanced cirrhosis. Hepatology 2002, 35: 630-634

40. Hirooka M, Koizumi Y, Miyake T, Watanabe T, Yoshida O, Tokumoto Y, Yukimoto A, Nakamura Y, Imai Y, Abe M, Hiasa Y: Nonalcoholic fatty liver with a hepatic arterial buffer response strongly associated with future metabolic disease. Hepatol Commun 2017, 1: $623-633$ 